\title{
The electrical properties of Au/GaN and PEDOT: PSS/GaN diodes
}

\author{
A. Sadoun ${ }^{1}$, I. Kemerchou ${ }^{2,3}$, S. Mansouri ${ }^{1}$, M. Chellali ${ }^{1}$ \\ ${ }^{1}$ Applied Microelectronics Laboratory, University of Sidi Bel Abbes, ALGERIA \\ ${ }^{2}$ Laboratory of analyses and control of energy systems and networks, University of Amar Telidji, ALGERIA. \\ ${ }^{3}$ Materials Science and Engineering Program, State University of New York at Binghamton, USA. \\ E-mail*: 3ali39@gmail.com

\begin{abstract}
-
In the present paper, using a numerical simulator, the simulation of Au/n-GaN and PEDOT: PSS/GaN structures were performed in a temperature at room temperature. The electrical parameters: barrier height, ideality factor, shunt resistance series, and resistance have been calculated using different methods: conventional I-V, Norde, Chattopadhyay, and Mikhelashvili. Statistical analysis showed that the Au/GaN structure has a barrier height of $(0.6 \mathrm{eV})$ which is higher compared with the PEDOT: PSS/GaN structure $(0.72 \mathrm{eV})$ and ideality factor (1.88 and $2.26)$ respectively. The values of resistance shunt were increased from $77150.056 \Omega$ to 11207586 $\Omega$. It is observed that the leakage current increased from $6.64 \mathrm{E}-5$ to $4.98926 \mathrm{E}-5 \mathrm{~A}$ at $-0.85 \mathrm{~V}$.
\end{abstract}

Keywords: Schottky diode; Au/n-GaN; PEDOT: PSS/GaN; (I-V), Norde, Cheung and Chattopadhyay methods; Leakage current; Resistance shunt.

Received: 10/12/2020 - Accepted: 15/12/2020

\section{Introduction}

In the development of electronic components such as Schottky diode, MOS, transistor and metal-isolatesemiconductor, GaN's are commonly used (MIS). et cetera. [1-3]. Gallium nitride is a very promising material for semiconductor materials with high strength, highfrequency and wide-bandgap and high electron velocity saturation. The Gallium nitride binary compound is a semiconductor direct bandgap with a lattice parameter = $4.52 \AA$ and $\mathrm{Eg}=3.22 \mathrm{eV}$ and $300 \mathrm{~K}$ belonging to the III$\mathrm{V}$ family [4]. This binary compound (LEDs), photodetectors (MSM), laser diodes, solar cell application, and field-effect microwave transistors [5-9] is the promising material in light-emitting diodes. GaN's high-frequency characteristics make it suitable for highfrequency and high-power applications. [10, 11]. Many theoretical and experimental studies on the production of devices for Schottky diodes have been carried out (Metal-GaN). Projects have investigated the electronic parameters and frequency dependent properties of $\mathrm{Au} /$ $\mathrm{NiO} / \mathrm{GaN}$ Schottky diodes in the range $1 \mathrm{kHz}-1 \mathrm{MHz}$ at different frequencies.
A group of researchers have studied the effect of the hafnium dioxide layer on the electrical properties of the diode $(\mathrm{Pd} / \mathrm{GaN})$ in a wide temperature range (270 $390 \mathrm{~K})$, they have also treated the effect of temperature (400-600 K) on the electrical properties of the $\mathrm{Au} /$ Ta2O5 / n-GaN structure. Another group have studied the electric transport and transport properties of the rare earth oxide intercalary diode $\mathrm{Au} / \mathrm{Y} 2 \mathrm{O} 3$ / n-GaN [13,14]. The same group of researchers studied the effect of annealing temperature on the electrical properties of $\mathrm{Au} /$ Ta2O5/ n-GaN of the metallic insulating semiconductor structure (MIS) [12].

In this paper, we present a theoretical analysis of the effects of PEDOT: PSS is given using forward I-V bias measurements on the electrical properties of the Schottky diode $(\mathrm{M} / \mathrm{n}-\mathrm{GaN})$ at a temperature $(300 \mathrm{~K})$. We studied the evolution of ideality factor $(n)$, barrier height $(\Phi b 0)$, shunt resistance, and series resistance (Rs) using (I-V), Norde, Chattopadhyay and Mikhelashvili methods. 


\section{Method}

The band gap $(\mathrm{Eg}=3.40 \mathrm{eV})$, electron affinity $(\chi=4.10)$,

Relative permittivity $\varepsilon=9.50$ ), Effective density of states in the conduction band $\left(\mathrm{Nc}=2.3 .10 \mathrm{E} 17 \mathrm{~cm}^{-3}\right)$ and Effective density of states in the valence band

$\left(\mathrm{Nv}=4.7 .10 \mathrm{E} 17 \mathrm{~cm}^{-3}\right)$ parameters used in the simulation for $\mathrm{Au} / \mathrm{n}-\mathrm{GaN}$ and PEDOT: PSS/GaN SBDs, , The simulator is based on a mathematical model $[13,14]$.

$\begin{array}{ll}> & \text { Bandgap model [15]. } \\ > & \text { Mobility model [16]. } \\ > & \text { Shockley-Read-Hall model [16]. } \\ > & \text { Auger recombination [17]. } \\ > & \text { Thermionic emission [19]. } \\ > & \text { Universal Schottky tunneling [20]. } \\ > & \text { Image force lowering [21]. }\end{array}$

\section{Result and discussions}

\subsection{Current-voltage (I-V) method}

The electrical characterization of Schottky diode devices was carried out at the temperature $300 \mathrm{~K}$. Figure 1 shows the results of semi-log forward and reverse bias (currentvoltage) characteristics of the $\mathrm{Au} / \mathrm{n}-\mathrm{GaN}$ and PEDOT: PSS/GaN. The current-voltage characteristics of an ideal SBD are given by thermionic emission theory[24, 25] [7,8]. Equation (1) can be written as an equation for the forward voltage applied (V > 3kT/q) (1). [24-26]:

$$
\mathrm{I}=\mathrm{I}_{0} \exp \left(\frac{-\mathrm{qV}}{\mathrm{kT}}\right)
$$

We could find the value of $\left(\mathrm{I}_{0}\right)$ by the plot $\ln (\mathrm{I})$ versus (v) at $\mathrm{v}=0$ volts. Then, by replacing the calculated $\left(\mathrm{I}_{0}\right)$ value in the equation (2), we could find the Schottky barrier height. You can extract the value of the ideality factor $(n)$ from the linear curve area $(\ln (I)-v)$.

$$
\mathrm{I}_{0}=\mathrm{AT}^{2} \mathrm{~A}^{*} \exp \left(\frac{\mathrm{q} \Phi_{\mathrm{b} 0}}{\mathrm{kT}}\right)
$$

Where A is the rectifier contact area, $\Phi_{\mathrm{b}}$ is the Schottky barrier height [24]. $A^{*}$ is the Richardson constant $\left(A^{*}\right.$ $=26.4 \mathrm{~A} / \mathrm{cm}^{2} \mathrm{~K}^{2}$ for $\left.\mathrm{n}-\mathrm{GaN}\right)$.

The values of barrier height and ideality factor, these values can be determined using the equation (3):

$$
n=\frac{q}{k T} \frac{d\left(V-I R_{S}\right)}{d(\ln I)}
$$

And the barrier height $\Phi_{\mathrm{bn}}$ is given by:

$$
\Phi_{b n}=\frac{q}{k T} \ln \left(\frac{A A^{*} T^{2}}{I_{0}}\right)
$$

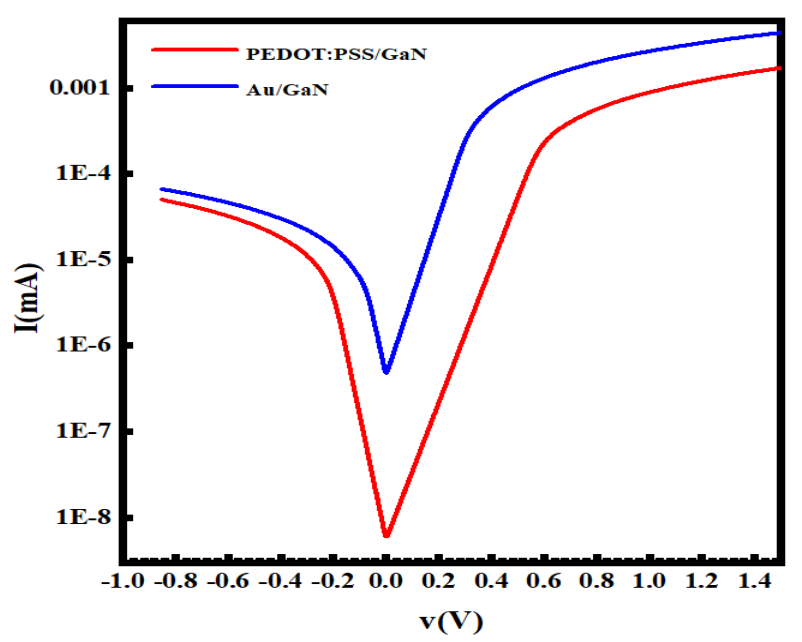

Figure 1. The semi-logarithmic reverse and forward bias currentvoltage characteristics for $\mathrm{Au} / \mathrm{n}-\mathrm{GaN}$ and PEDOT: PSS/GaN SBD in the temperature (300K)

\subsection{Method of Norde}

The Norde approximation method is defined by equation (5)[27]. This estimate is based on adjusted forward plots (I-V) that can be used to measure the height barrier:

$$
\mathrm{F}(\mathrm{v})=\frac{\mathrm{v}}{\gamma}-\frac{\mathrm{kT}}{\mathrm{q}} \ln \left(\frac{\mathrm{I}(\mathrm{v})}{\mathrm{AA}^{*} \mathrm{~T}^{2}}\right)
$$

Where $\gamma$ is an integer (dimensionless) greater than $\mathrm{n}$ and I (V) present the current which is acquired from the (I-V) curve. In this approximation, height barrier values can be determined using the equation $(6)$ [27, 28]:

$$
\Phi_{\mathrm{b}}=\mathrm{F}\left(\mathrm{v}_{0}\right)+\left[\frac{\mathrm{v}_{0}}{\gamma}-\frac{\mathrm{kT}}{\mathrm{q}}\right]
$$

Where $(n)$ value is obtained from the $\ln (\mathrm{I})-\mathrm{V}$ curve, $\mathrm{F}\left(\mathrm{v}_{0}\right)$ is the minimum point of $\mathrm{F}(\mathrm{V})$ as a function of $\mathrm{V}$.

From Figure 2, we can determine values barrier heights, at the temperature of $300 \mathrm{~K}$. was obtained and collected in Table 1 . 


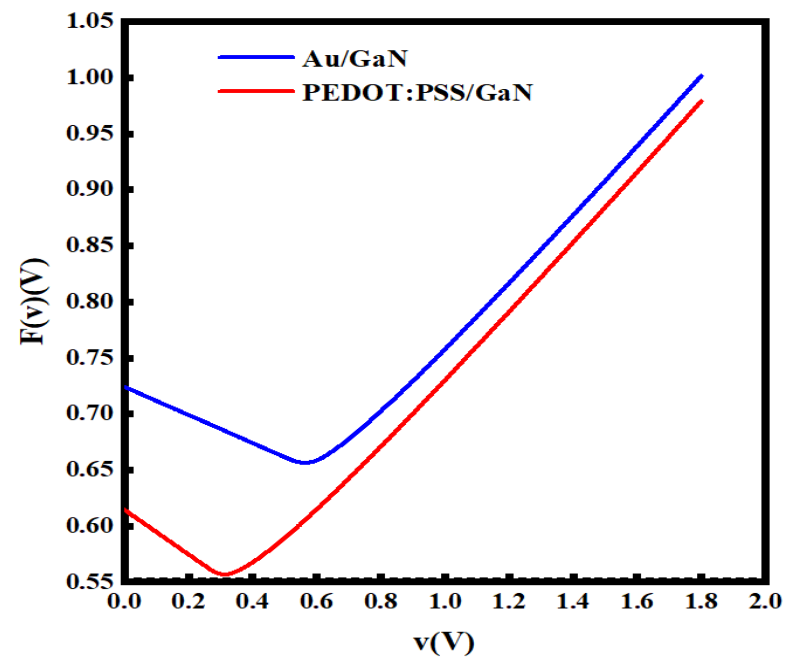

Figure 1. $\mathrm{F}(\mathrm{V})$ as a function of $\mathrm{V}$ of $\mathrm{Au} / \mathrm{n}-\mathrm{GaN}$ and PEDOT: PSS/GaN structures

\subsection{Model of Chattopadhyay}

The Chattopadhyay model is defined by equation (6) this approximation can be used to determine heights barrier and the ideality factor this values, can be calculated from the equation (7) :

$$
\varphi \mathrm{b}=\Psi_{\mathrm{s}}(\mathrm{JC}, \mathrm{VC})+\mathrm{C} 2 \mathrm{VC}+\mathrm{Vn}-\mathrm{KT} / \mathrm{q}
$$

The inverse of the ideality factor $\left(\mathrm{C}_{2}\right)$ can be calculated by equation (8):

$$
\mathrm{C}_{2}=\frac{1}{\mathrm{n}}=\left(\frac{d \Psi_{s}}{d V}\right)_{\mathrm{Jc}, \mathrm{Vc}}
$$

Where $V_{n}$ is the potential difference between the Fermi level and the bottom of the conduction band $\left(\left(E_{F}\right)-E_{c}\right)$, which can be calculated from equation (9):

$$
\mathrm{V}_{\mathrm{n}}=\frac{k T}{q} \operatorname{Ln}\left(\frac{N_{c}}{N_{d}}\right)
$$

Where, $\left(\mathrm{N}_{\mathrm{c}}\right.$ and $\left.\mathrm{N}_{\mathrm{d}}\right)$ present the effective conduction band density of states and the carrier concentration, respectively.

The value of surface potential $\Psi_{\mathrm{s}}$ can be determined from equation (10):

$$
\Psi_{\mathrm{s}}=\frac{\mathrm{KT}}{\mathrm{q}} \ln \left(\frac{A A^{*} T^{2}}{I}\right)-\mathrm{Vn}
$$

With the aid of equations (9) and (10), the values of ideality factor $(n)$ and barrier height were obtained and collected in Table 1.

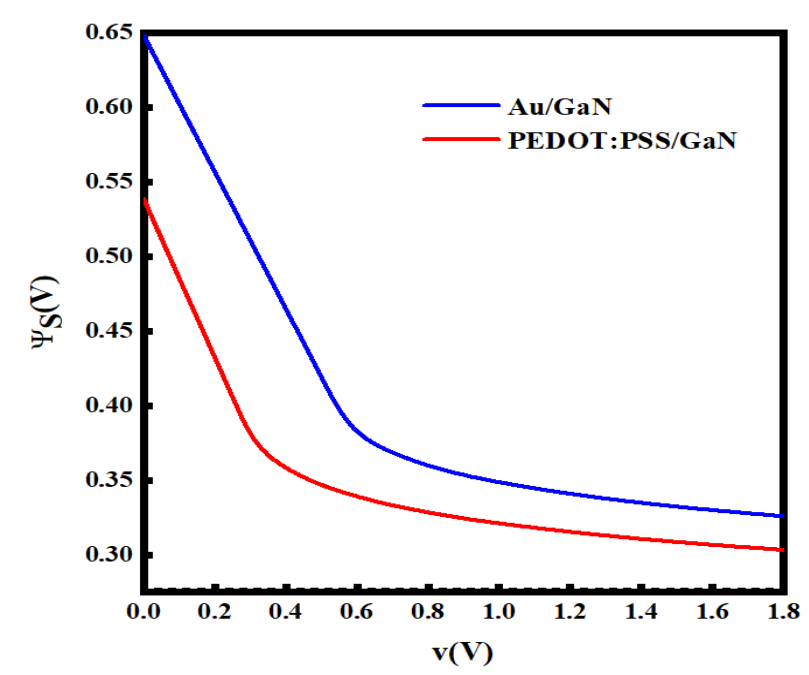

Figure 2. Surface potential-forward voltage curves of the $\mathrm{Au} / \mathrm{n}-\mathrm{GaN}$ and PEDOT: PSS/GaN structures at $\mathrm{T}=300 \mathrm{~K}$

\subsection{Mikhelashvili method}

Mikhelashvili's method for determination of the barrier height, ideality factor, and the series resistance. This method is based on the equation (11):

$$
\theta(v)=\frac{d(\ln (I))}{d(\ln (v))}
$$

The barrier height and the ideality factor are obtained from equations (12) and (13)

$$
\begin{gathered}
\Phi_{\mathrm{b}}=\frac{\mathrm{kT}}{\mathrm{q}}\left[\theta_{\mathrm{m}}+1-\ln \left(\frac{\mathrm{I}_{\mathrm{m}}}{\mathrm{AA}^{*} \mathrm{~T}^{2}}\right)\right] \\
\mathrm{n}=\frac{q \mathrm{v}_{\mathrm{m}}\left(\theta_{\mathrm{m}}-1\right)}{\mathrm{kT} \theta_{m}^{2}}
\end{gathered}
$$

Where $\left(\theta_{\mathrm{m}}\right.$ and $\left.\mathrm{V}_{\mathrm{m}}\right)$ are the coordinates of the maximum point in $\theta(\mathrm{V})$ versus $\mathrm{V}$ plot. at temperatures $(300 \mathrm{~K})$. The series resistance (Rs) is obtained from equation (14):

We can determine values barrier heights and series resistance, at the temperature of $300 \mathrm{~K}$ and presented in Table 1

$$
R_{s}=\frac{v_{\mathrm{m}}}{\mathrm{I}_{m} \theta_{m}^{2}}
$$




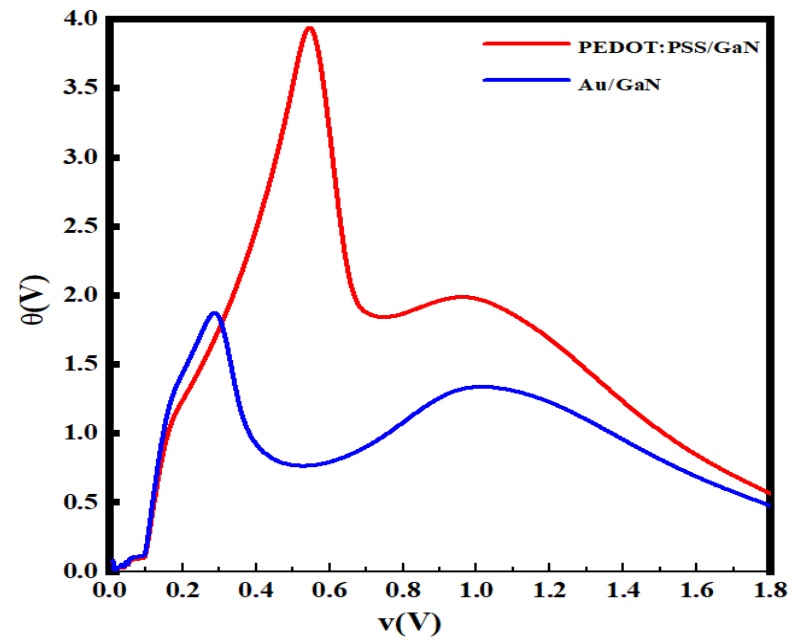

Figure 3. Mikhelashvili's plots for (a) the Au/n-GaN and PEDOT: $\mathrm{PSS} / \mathrm{GaN}$ structures at $\mathrm{T}=300 \mathrm{~K}$

We computed values of ideality factor, barrier height and series resistance and reported it in Table 1 . The obtained results using the $\mathrm{I}-\mathrm{V}$ approach in temperatures $300 \mathrm{~K}$ shows an increase of barrier height (from 0.6 to $0.72 \mathrm{eV}$ ), an increase of ideality factor (n) (from 1.88to 2.26) and an increase of series resistance (RS) (from 318 to $608.5 \Omega)$. We observed that an increase in $(\mathrm{T}=300 \mathrm{~K})$ is accompanied by a decrease in the ideality factor and an increase in the barrier height for all methods [20]. The shunt resistance and series resistance are the other two important parameters for the SBD.

Table 1. The obtained values of saturation current, barrier height, ideality factor, and series resistance for $\mathrm{Au} / \mathrm{n}-\mathrm{GaN}$ and PEDOT: PSS/GaN structures

\begin{tabular}{|c|l|l|l|l|l|l|l|l|}
\hline & \multicolumn{2}{|l|}{ ideality factor } & \multicolumn{2}{l|}{ saturation current } & \multicolumn{2}{l|}{ barrier height } & \multicolumn{2}{l|}{ series resistance } \\
\hline & A1 & A2 & A1 & A2 & A1 & A2 & A1 & A2 \\
\hline V-I & 1.88 & 2.26 & $4.4 \mathrm{E}-7$ & $5.55 \mathrm{E}-9$ & 0.66 & 0.72 & 318 & 608.5 \\
\hline Norde & -- & -- & -- & -- & 0.68 & 0.94 & -- & -- \\
\hline Chattopadhyay & 2.22 & 1.78 & -- & -- & 0.60 & 0.85 & -- & -- \\
\hline Mikhelashvili & 2.17 & 2.10 & -- & -- & 0.59 & 0.82 & 401 & 432 \\
\hline
\end{tabular}

Figure 5 represents Resistance $\mathrm{R}_{\mathrm{Sh}}$ as a function of voltage $\mathrm{V}$ and it is noted that the $\mathrm{R}_{\mathrm{Sh}}$ values are found to be $77150.056 \Omega$ and $11207586 \Omega \mathrm{Au} / \mathrm{n}-\mathrm{GaN}$ and PEDOT: PSS/GaN structures, respectively.
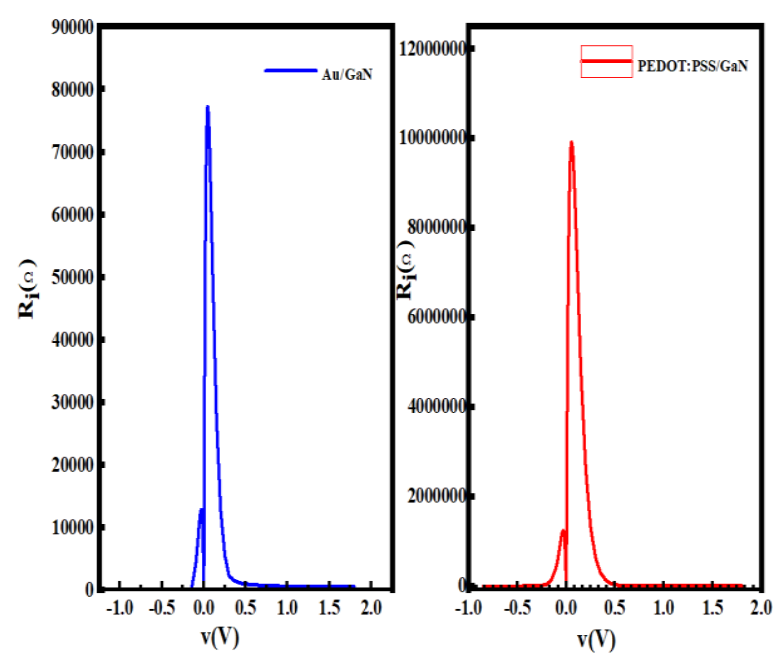

Figure 5. voltage reliant device resistance

\section{Conclusion}

We reported in this paper the electrical characterization of $\mathrm{Au} / \mathrm{GaN}$ and PEDOT: PSS/GaN structures. We demonstrated that the I-V curves of these diodes. A low barrier height and the leakage current were obtained. The barrier height, ideality factor, and series resistance are also estimated by (I-V), Norde's, Chattopadhyay's, and Mikhelashvili's methods. Results show that the Schottky emission is the dominant conduction mechanism. The statistical analysis is employed to extract the barrier Heights were $0.6 \mathrm{eV}$ and $0.72 \mathrm{eV}$ from $\mathrm{I}-\mathrm{V}$ measurements respectively. It is observed that the leakage current increased from $6.64 \mathrm{E}-5$ to $4.98926 \mathrm{E}-5 \mathrm{~A}$ at $-0.85 \mathrm{~V}$.

\section{References}

[1] S. Asubay, Ö. Güllü, A. Türüt, "Determination of the laterally homogeneous barrier height of metal/ p- InP Schottky barrier diodes", Vacuum, Vol. 83, No. 3, 2009, pp. 1470-1474.

[2] J. Schleeh, G. Alestig, J. Halonen, A. Malmros, B. Nilsson, P. Nilsson, J.P. Starski, N. Wadefalk, H. Zirath, J. Grahn, "Cooled integrated circuit amplifies with lowest noise so far", IEEE Electron Device Letters, Vol. 33, No. 5, 2012, pp. 664-666.

[3] F. Acar, A. Buyukbas-Ulusan, A. Tataroglu, "properties of $\mathrm{Al} /$ coumarin doped $\mathrm{Pr}_{2} \mathrm{Se}_{3}-\mathrm{Tl}_{2} \mathrm{Se} / \mathrm{p}$-Si devices", Journal of Materials Science: Materials in Electronics, Vol. 29, No. 15, 2018, pp. 1-8.

[4] S. Adachi, "Group-IV, III-V and II-VI semiconductors", John Wiley \& Sons, 2009, ISBN: 978-0-470-74369-0.

[5] K. Hattori, Y. Torii, "platform of peer-reviewed scholarly literature", Solid-State Electronics, Vol. 34, No. 5, 1991, pp. 429-534. 
[6] A. Singh, K. Reinhardt, W. Anderson, "Temperature dependence of the electrical characteristics of $\mathrm{Yb} / \mathrm{p}-\mathrm{InP}$ tunnel metal-insulator-semiconductor junctions", Journal of applied physics, Vol. 68, 1990, pp. 3475-3483.

[7] T. Enoki, H. Yokoyama, Y. Umeda, T. Otsuji, "UltrahighSpeed Integrated Circuits Using InP-Based HEMTs ", Journal of applied physics, Vol. 37, No. 3B, 1998, pp. 1359-1364.

[8] K. Pande, "Characteristics of MOS solar cells built on /ntype/ In P substrates", IEEE Transactions on Electron Devices, Vol. ED-27, 1980, pp. 631-634.

[9] K. Zeghdar, L. Dehimi, A. Saadoune, N. Sengouga, "IInhomogeneous barrier height effect on the currentvoltage characteristics of an Au/n-InP Schottky diode ", Journal of Semiconductors, Vol. 36, No. 12, 2015, article id. 124002

[10] N. Balaram, V.R. Reddy, P.S. Reddy, V. Janardhanam, C.J. Choi, "Microstructural, chemical states and electrical properties of $\mathrm{Au} / \mathrm{CuO} / \mathrm{n}$-InP heterojunction with a cupric oxide interlayer", Vacuum, Vol. 152, 2018, pp. 15-24.

[11] M. Benchehima, H. Abid, A. Sadoun, A.C. Chaouche, "Optoelectronic properties of aluminium bismuth antimony ternary alloys for optical telecommunication applications: First-principles calculation ", Computational Materials Science, Vol. 155, 2018, pp. 224-234

[12] M. Cao, P.V. Voorde, M. Cox, W. Greene, Boron diffusion and penetration in ultrathin oxide with poly-Si gate, IEEE Electron Device Letters, Vol 19, 1998, pp. 291293.

[13] S. Atlas, Silvaco International Software, Santa Clara, CA, USA, 2005.

[14] A. Sadoun, S. Mansouri, M. Chellali, A. Hima, and Z. Benamara, "The effect of introduction of $\mathrm{HfO} 2$ on the electrical characterization of the $\mathrm{Pt} / \mathrm{HfO} 2 / \mathrm{n}-\mathrm{GaN}, "$ in 2018 International Conference on Communications and Electrical Engineering (ICCEE) ", 2018, pp. 1-4.

[15] A.U.s. Manual, Silvaco Int., Santa Clara, CA, 2008.

[16] J. Dziewior, W. Schmid, "Auger coefficients for highly doped and highly excited silicon", Applied Physics Letters, Vol 31, 1977, pp. 346-348.

[17] F. Zappa, P. Lovati, A. Lacaita, "Temperature dependence of electron and hole ionization coefficients in InP", Proceedings of 8th International Conference on Indium Phosphide and Related Materials, IEEE, 1996, pp. 628631.

[18] C. Crowell, S. Sze, "Current transport in metalsemiconductor barriers", Solid-State Electronics, Vol 9, 1966, pp. 1035-1048.

[19] M. Ieong, P.M. Solomon, S. Laux, H.-S. Wong, D. Chidambarrao, "Comparison of raised and Schottky source/drain MOSFETs using a novel tunneling contact model", International Electron Devices Meeting 1998. Technical Digest (Cat. No. 98CH36217), IEEE, 1998, pp. 733-736.

[20] S.M. Sze, K.K. Ng, Book: Physics of semiconductor devices, Print ISBN:9780471143239, John Wiley \& sons, 2006.
[21] A. Sadoun, S. Mansouri, M. Chellali, N. Lakhdar, A. Hima, and Z. Benamara, "Investigation, analysis and comparison of current-voltage characteristics for $\mathrm{Au} / \mathrm{Ni} / \mathrm{GaN}$ Schottky structure using IVT simulation", Materials Science-Poland, Vol. 37, 2019, pp. 496-502.

[22] A. Sadoun, I. Kemerchou, "Extraction of the electrical parameters of the $\mathrm{Au} / \mathrm{InSb} / \mathrm{InP}$ Schottky diode in the temperature range $(300 \mathrm{~K}-425 \mathrm{~K})$ ", International Journal of Energetica (IJECA), Vol. 5, No. 1, 2020, pp. 31-36.

[23] R. Padma, B. P. Lakshmi, M. S. P. Reddy, and V. R. Reddy, "Electrical and structural properties of $\mathrm{Ir} / \mathrm{Ru}$ Schottky rectifiers on n-type InGaN at different annealing temperatures", vol. 56, 2013, pp. 64-76.

[24] V. R. Reddy, V. Manjunath, V. Janardhanam, Y.-H. Kil, and C.-J. Choi, "Electrical properties and current transport mechanisms of the Au/n-GaN Schottky structure with solution-processed high-k BaTiO3 interlayer", Vol. 43, 2014, pp. 3499-3507.

[25] H. Norde, "A modified forward I- V plot for Schottky diodes with high series resistance", Journal of Applied Physics, Vol 50, 1979, pp. 5052.

[26] A. Kocyigit, I. Orak, Z. Çaldıran, A. Turut, "Currentvoltage characteristics of $\mathrm{Au} / \mathrm{ZnO} / \mathrm{n}$-Si device in a wide range temperature", J Mater Sci: Mater Electron, Vol 28, 2017, pp. 17177-17184.

[27] P. Chattopadhyay, "A new technique for the determination of barrier height of Schottky barrier diodes", Solid-state electronics, Vol 38,1995, pp. 739-741.

[28] Ş. Karataş, N. Yildirim, A. Türüt, "Electrical properties and interface state energy distributions of $\mathrm{Cr} / \mathrm{n}$-Si Schottky barrier diode", Superlattices and Microstructures, Vol 64, 2013, pp. 483-494. 